\title{
ACRL's 1984 National Conference: Call for Participation
}

Myths and realities: have the academic and research libraries of the 80 s exchanged new myths for old myths? Has advanced technology produced its own myths? Planning for academic libraries should be based on realities, but how many myths exist in the guise of reality? The 1984 ACRL National Conference in Seattle will explore these issues. Contributed papers are a major feature of the Conference. Alternative formats such as symposia or panels will be considered. Papers or proposals for alternative format presentations are welcome on issues surrounding the theme.

The following are examples of possible topics and some related myths/realities.

-Information and the Electronic Age: cost is a barrier to library automation; the book is obsolete; information is free; collection development policies are useful.

- Libraries: the library is the heart of the university; consultants solve your problems; libraries share resources.

- Library Users and Services! professional reference service is required by users; only librarians can do online searching; bibliographic instruction is ineffective.

-Bibliographic Control and Access: Controlled vocabulary is necessary; all elements in the MARC record are needed for effective access; subject access is unnecessary.

-The Profession: Faculty status assures professionalism; continuing education is essential; burnout is a cop-out.

Each paper submitted will be reviewed by at least two referees as part of the selection process. Criteria for selection include clarity, originality, relevance to the theme, and suitability for oral presentation.

Papers should be a maximum length of 2,500 words. Papers accepted by the referees and the Contributed Papers Committee will be returned to authors for final editing and preparation of camera-ready copy to be included in the conference proceedings. Proposals for presentation in alternative formats will be reviewed by the Contributed Papers and Conference Executive Committees. Those selected will not be included in the conference proceedings.

Papers may be scheduled for presentation more than once. Each presentation will last 20 minutes. Presenters must attend the conference at their own expense. Additional instructions to authors will be mailed upon receipt of the Notice of Intention to Submit a Paper.

Schedule for submission:

June 1, 1983-Notice of Intention to Submit a Paper.
October 1, 1983-Papers due.

December 1, 1983-Notification of acceptance.

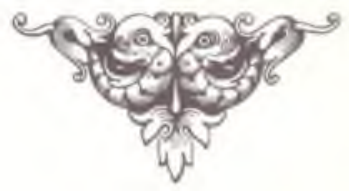

\section{Seattle ' 84}

A central feature of ACRL's third national conference to be held in Seattle, April 4-7, 1984, will be the contributed papers. The call

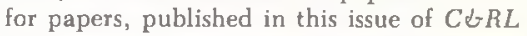
News, suggests some issues that might serve as the germ of an idea for papers or that might lead to other ideas and issues. The conference theme, "Academic Libraries: Myths and Realities," is to be the focus of the contributed papers, as well as of the other sessions at the conference. Librarians from all types of academic and research libraries are encouraged to submit papers.

The Contributed Papers Committee will select referees whom it will ask to review papers written in their particular field of expertise. Following the review by the referees, the Committee will make the final determination of the papers to be given at the conference. The anonymity of the authors will be scrupulously maintained throughout the process of review and final selection by removing from the papers all names or other things that might possibly serve to identify an author or his/her library.

Abstracts of the papers to be given at the conference will be published in the January 1984 issue of $C \triangleleft R L$ News.

The Contributed Papers Commmittee will be responsible for issuing the conference proceedings, which will include only the theme session talks and the papers. In order to speed the issuance of the proceedings and reduce their cost, the authors of the papers will be required to edit their papers following the review by the referees and selection by the committee, and then prepare camera-ready copy for inclusion in the proceedings. Full conference registration will include a copy of the proceedings. 


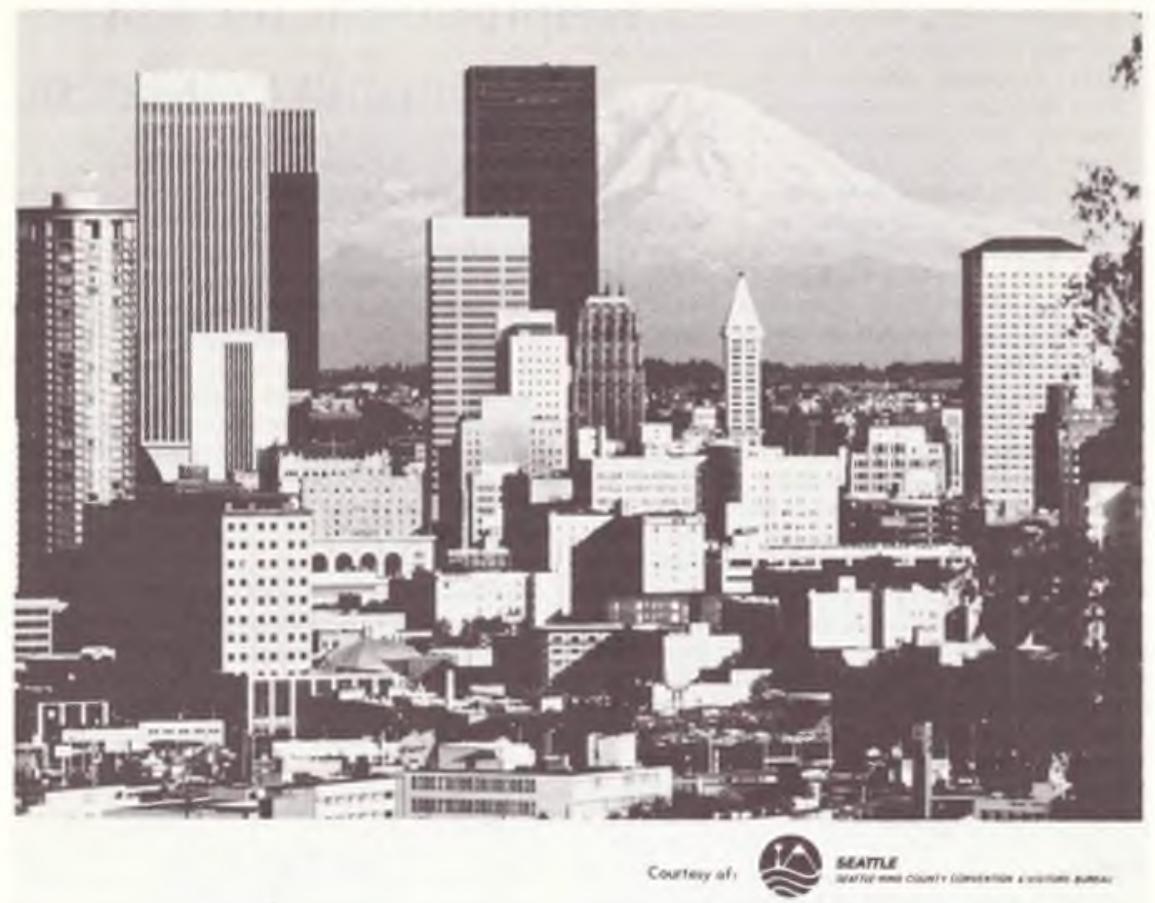

Seattle's skyline shows the city's mixture of modern architecture and unique historical buildings. Majestic Mt. Rainier, 60 miles from Seattle, soars 14,000 feet above the skyline.

\section{Notice of Intention to Submit a Paper}

I intend to submit a paper for the ACRL 1984 National Conference in Seattle.

Name. Mailing Address

Work phone number

Home phone number

Tentative paper title

Attach a brief description of the proposed paper (no more than 200 words).
Mail this form before June 1, 1983 to:

ACRL Contributed Papers Chairman Sarah C. Michalak

Suzzallo Library; FM-25

University of Washington Libraries Seattle, Washington 98195 (206) $543-5071$ 